\title{
HOMENAJE A LUIS ASTEY, IN MEMORIAM Mauricio Beuchot*
}

Como un homenaje a mi amigo Luis Astey, hablaré un poco de su trayectoria académica, que fue muy sólida, y después hablaré un poco de su labor como humanista clásico, esto es, en lo referente a las lenguas y literaturas griega y latina. Me centraré sobre todo en su trabajo como traductor del latín medieval, pues me tocó presentar los principales libros que en esa área publicó.

Luis Astey nació el 12 de abril de 1921 en Guadalajara, Jalisco. Hizo estudios de derecho en la Universidad de esa ciudad. Dejando de lado las lides jurídicas, marchó a París a especializarse en literatura dramática latina medieval, en la Universidad de la Sorbona, concretamente en la École Pratique des Hautes Études, de 1947 a 1948. Diez años después realizó una investigación dirigida sobre literatura griega clásica, en la Harvard Graduate School, de 1959 a 1960. Como se ve, Luis tenía excelentes bases para desarrollar su labor de estudio y traducción de dramas medievales.

En cuanto a su labor docente, fue profesor en el Departamento de Humanidades del Instituto Tecnológico y de Estudios Superiores de Monterrey, de 1945 a 1973; profesor de Literatura griega clásica en la Facultad de Filosofia y Letras de la Universidad de Nuevo León, de 1951 a 1973; también es muy conocida la importante labor que Luis desarrolló como jefe de la biblioteca del Tecnológico regiomontano,

* Instituto de Investigaciones Filológicas, UNAM. 
MAURICIO BEUCHOT

dejando un acervo amplio y bien seleccionado para muchas generaciones que allí se han formado.

Fue asimismo profesor de literatura medieval en la Facultad de Filosofía y Letras de la UNAM, en licenciatura de 1973 a 1986, y en el posgrado a partir de 1981. Además, fue profesor e investigador en el Departamento de Estudios Generales del Instituto Tecnológico Autónomo de México, desde 1973; e investigador en el Centro de Estudios Lingüisticos y Literarios del Colegio de México desde 1977.

En el ámbito del griego clásico publicó: "La Teogonía hesiódica", en Cuadernos de Humanidades (Monterrey, N.L.), 1 p. 45-119; "Sofistas, dioses y literatura", en Estudios (México, D.F.), 2 (1985), p. 77-83, 3 y 4 (1986), p. 91-104 y 49-84. En relación con el latín medieval, "Hrotsvitha de Gandersheim, Dulcidio (Dulcitius)", en Cuadernos de Investigación Humanistica (Monterrey, N.L.), 1 (1966), p. 175-202; "Sponsus": un drama medieval latino-románico, Monterrey: Poesía en el Mundo, 1967 (2a. ed., 1969); Hrotsvitha de Gandersheim, "Calimaco", Monterrey: Poesía en el Mundo, 1969; "El Danielis hudus de la Catedral de Beauvais", en Humanitas, 10 (1969), p. 307-325; El "Ludus de Nativitate" de Benediktbeuern, Monterrey: Poesía en el Mundo, 1970; "Peregrinus": tres versiones, Monterrey: Poesía en el Mundo, 1971; Dramas latinos medievales del ciclo de Navidad, Monterrey: ITESM, 1970; Una edición del "Pergamino Vindel", Monterrey: Poesía en el Mundo, 1978; Hrotsvitha de Gandersheim, Los seis dramas, México: FCE-ITAM, 1990; "El Ordo Virtutum de Hildegard von Bingen", en R. Olea Franco y J. Valender (eds.), Reflexiones lingüisticas y literarias, II: Literatura, México: El Colegio de México, 1992, p. 17-52; Dramas litúrgicos del Occidente medieval, México: El Colegio de México-CONACYTITAM, 1992; Los tres dramas de Hilario y otros tres dramas temáticamente afines, México: Instituto de Investigaciones Filológicas de la UNAM, 1995.

El trabajo de Luis Astey es sumamente cuidadoso. Sus traducciones son muy fieles, sus introducciones y notas muy eruditas. Reúne las condiciones para trabajar de manera sobresaliente en el campo de su especialidad, que es el neolatín o latín medieval. 
En esta área he podido apreciar tres libros del Dr. Astey, que son Hrotsvitha de Gandersheim, Los seis dramas, traducción, introducción y notas de Luis Astey, México: FCE-ITAM, 1990; Dramas litúrgicos del Occidente medieval, México: El Colegio de MéxicoCONACYT-ITAM, 1992; y Los tres dramas de Hilario y otros tres dramas temáticamente afines, México: UNAM, 1995.

El primer libro, el de los seis dramas de Hrotsvitha de Gandersheim, es una serie de piezas teatrales inspiradas por la imitación de Terencio, con la seriedad y pulcritud que caracterizaron a ese autor latino. Astey nos hace entrar en el contexto histórico de la autora; más aún, nos hace quedar cautivados por ella, como una de esas extrañas monjas de la Alta Edad Media que eran tan cultas, como Hildegarda de Binghem, y que nos recuerdan mucho a nuestra Sor Juana.

El segundo libro, el de los dramas litúrgicos del Occidente medieval es, ya solamente por su voluminosidad, una compilación muy amplia de estas piezas medievales que acompañaban las ceremonias de algunos tiempos o fiestas religiosos. Así, por ejemplo, los dramas que representaban la resurrección de Jesucristo, y que van marcando los diferentes pasos que señala el relato evangélico, como la visita al sepulcro por María Magdalena, la visión del sepulcro vacío, las palabras del ángel que explicaba el acontecimiento, el encuentro con el Señor resucitado. Otro es el oficio de los peregrinos, que narra el suceso de Emaús, en el que Cristo resucitado se encuentra a dos de sus discípulos que viajan al poblado de Emaús, cercano a Jerusalén; les pregunta por qué van tristes, a lo que ellos responden con la noticia de la muerte y fracaso de Jesús; él les explica con las escrituras que así debía suceder; finalmente ellos lo invitan a pasar a su casa, cuando parecía que iba a continuar su camino, y lo reconocen o se les revela como el Señor cuando lo hacen partir el pan. Otros son el oficio de la ascensión de Cristo a los cielos y el de Pentecostés, o la venida del Espíritu Santo sobre los apóstoles. Otro es el riquísimo orden de la Navidad, con sus pastores, ángeles y demás elementos. Otros corresponden a personajes bíblicos, como los órdenes de Raquel y de algunos profetas. 


\section{MAURICIO BEUCHOT}

Los dramas de Hilario son no solamente interesantes por su contenido, sino por ser éste un discípulo del célebre filósofo medieval Pedro Abelardo. Representan la resurrección de Lázaro por Jesús; unas escenas relativas a la imagen de San Nicolás; y la historia bíblica de Daniel. De inmenso relieve es el Lvdus svper Iconia Sancti Nicolai, esto es, una pieza sobre la imagen o icono de San Nicolás de Bari, el cual es visto precisamente como el enclave entre el mundo de la Iglesia de Occidente y la de Oriente, dada a los iconos. Un bárbaro, es decir, un pagano, va a salir de viaje, y encomienda sus pertenencias a una imagen de San Nicolás que se encuentra en el camino. Se va; pasan unos ladrones y se roban todo; cuando él regresa, se queja de lo mal que la imagen del santo le guardó sus cosas. Reclama furiosamente a la imagen y hasta la golpea. San Nicolás se aparece a los ladrones y los insta a devolver las cosas, amenazándolos con aparecerse a todo el pueblo y descubrirlos. Ellos, con gran temor, restituyen lo robado, y el bárbaro agradece a la imagen este milagro tan notable. Pero San Nicolás se le aparece y le dice que más bien debe dar gracias a Dios, y no a él. Reconoce todo esto el bárbaro, y determina dejar su paganismo para abrazar la religión cristiana. Ciertamente se trata de unos

154 dramas muy rudimentarios, ingenuos y candorosos; pero en ellos se encuentra una gran belleza, la belleza de aquello que se entrega con autenticidad.

Pues bien, en síntesis y conclusión, el acceso a esos tesoros literarios lo debemos a nuestro recordado amigo Luis Astey. Él fue quien se dio a la ardua labor de conseguir los textos, en diversas bibliotecas de Europa, a las que su conocimiento lo llevó; se ocupó en hacer cuidadosas traducciones de los mismos; y efectuó eruditas introducciones y notas para que pudiéramos comprenderlos mejor. En este sentido, la cultura humanista mexicana le está en deuda. 